\title{
Metodología Sencilla para Evaluar Bioactividad de Ácidos Húmicos obtenidos de Lignito Mediante Extracción Alcalina y Bacterias Solubilizadoras de Carbón
}

\author{
Nelson O. Valero(1, 2)* José A. Salgado $^{(1)}$ y Dianni Corzo(2) \\ (1) Facultad de Ciencias Básicas y Aplicadas, Universidad de La Guajira, Km 5 vía a Maicao, La Guajira, \\ Colombia. (e-mail: nvalerov@uniguajira.edu.co) \\ (2) Grupo de Investigación en Microbiología Agrícola y Ambiental, Universidad Popular del Cesar, Dg. 21 \# \\ 29-92, Valledupar, Colombia.
}

*autor a quien debe ser dirigida la correspondencia

Recibido Nov. 15, 2017; Aceptado Ene. 19, 2018; Versión final Feb. 27, 2018, Publicado Ago. 2018

\begin{abstract}
Resumen
En este trabajo se probó un test rápido para evaluar la bioactiviad de ácidos húmicos (AH) obtenidos a partir de un carbón lignito a través de dos métodos: 1) mediante extracción química con $\mathrm{NaOH}(\mathrm{AH}-\mathrm{Q})$ y 2) mediante actividad de una cepa bacteriana (Enterobacter aerogenes). Para ello se determinó la capacidad de los AH para ocasionar la elongación celular en coleóptilos de trigo, así como la capacidad para inducir la proliferación y alargamiento de raíces a partir de semillas pregerminadas. Se probaron concentraciones de

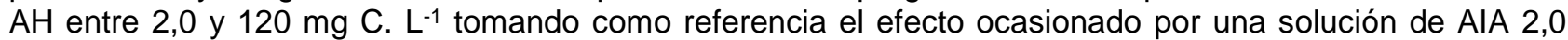
$\mathrm{mgL}^{-1}$. Se encontró que el tratamiento con $\mathrm{AH}-\mathrm{Q}$ a $40 \mathrm{mg} \mathrm{C} . \mathrm{L}^{-1}$ ocasionó un mayor alargamiento de coleóptilos y raíces, mientras que una concentración de $20 \mathrm{mg} \mathrm{C}^{-\mathrm{L}^{-1}}$ de AH-B presentó bioactividad superior en todos los parámetros evaluados. Los resultados indican que los AH evaluados presentan bioactividad que depende del tipo de extracción y de la concentración aplicada.
\end{abstract}

Palabras clave: lignito; ácidos húmicos; bacterias solubilizadoras; bioactividad, coleóptilos de trigo

\section{Simple Methodology to Evaluate Bioactivity of Humic Acids obtained from Lignite through Alkaline Extraction and Coal Solubilizing Bacteria}

\begin{abstract}
In this work a rapid test to evaluate the bioactivity of humic acids (HA) obtained from a lignite coal through two methods was tested: 1) through chemical extraction with $\mathrm{NaOH}(\mathrm{HA}-\mathrm{Q})$, and 2) by activity of a bacterial strain (Enterobacter aerogenes). For this, the capacity of the HAs to enhance cellular elongation in coleoptiles of wheat was determined, as well as the ability to induce root proliferation and elongation on pregerminated seeds; AH concentrations between 2,0 and $120 \mathrm{mg} \mathrm{C}^{-1} \mathrm{~L}^{-1}$ were tested with reference to the effect enhanced by an AIA 2,0 mgL-1 solution. It was found that treatment with $\mathrm{AH}-\mathrm{Q}$ at $40 \mathrm{mg} \mathrm{C}^{-1} \mathrm{~L}^{-1}$ enhance a greater elongation of coleoptiles and roots, whereas a concentration of $20 \mathrm{mg} \mathrm{C}^{-\mathrm{L}^{-1}}$ of AH-B enhanced highest bioactivity in all growth parameters evaluated. The results indicate that the evaluated HAs exhibit bioactivity that depends on the type of extraction and on the concentration applied.
\end{abstract}

Keywords:lignite; humic acids; solubilizing bacteria; bioactivity, wheat coleoptils 


\section{INTRODUCCIÓN}

Los ácidos húmicos $(\mathrm{AH})$ son una fracción de la materia orgánica humificada $(\mathrm{MOH})$ cuya estructura se puede explicar como una mezcla heterogénea de moléculas de bajo peso molecular producidas por la descomposición parcial y reorganización supramolecular de la materia orgánica depositada en el suelo, entre otras propiedades, los $\mathrm{AH}$ presentan la capacidad de promover el crecimiento vegetal como consecuencia de las interacciones químicas (hidrofílicas o hidrofóbicas) que se dan entre ellas (Piccolo, 2012). Estas sustancias son solubles en soluciones alcalinas y comúnmente tienen una predominancia de compuestos hidrofóbicos (Piccolo, 2002).

Canellas et al. (2015) consideran que el uso de sustancias húmicas (SH) podría contribuir a la intensificación en la agricultura ecológica, en miras a suplir la actual necesidad de alimentos en el marco de la degradación de los ecosistemas como consecuencia del cambio climático, reduciendo u optimizando al máximo el uso de fertilizantes químicos y otro tipo de subsidios energéticos a los agroecosistemas. Se ha documentado el efecto like-auxin de los $\mathrm{AH}$ como una respuesta fisiológica de la planta similar a la ocasionada por las auxinas (Muscolo et al., 1999; Nardi et al., 2002), siendo esto un aspecto muy importante a nivel fisiológico, ya que las auxinas podrían estar implicadas en todos los procesos del desarrollo y crecimiento de las estructuras vegetales (Gallavotti, 2013). Los AH se han relacionado con la estimulación de la producción y elongación de raíces, lo que a su vez repercute en los procesos que definen la arquitectura de la raíz, la toma de agua, nutrientes y las asociaciones que establece la planta con los microorganismos del suelo en la rizósfera y que adicionalmente, pueden afectar diferentes rutas del metabolismo vegetal e influir sobre la arquitectura total de la planta (Canellas y Olivares, 2014; Canellas et al., 2015). Por otra parte se sabe que el ácido indol acético (AIA) puede establecer interacciones hidrofóbicas con otros compuestos (Delatorre et al., 2013), además, a través del proceso de humificación los microorganismos del suelo contribuyen preferencialmente a la formación de SH hidrofóbicas, por lo tanto este hecho podría favorecer la interacción de las SH con el AIA presente en el suelo, que luego podría ser utilizado por la planta. Sobre este aspecto, Nardi et al. (2017) señalan la posibilidad de que la bioactividad de las SH se deba a la presencia de moléculas de auxinas atrapadas en la supraestructura húmica.

La capacidad de la $\mathrm{MOH}$ para estimular el crecimiento vegetal a través de diferentes mecanismos se ha denominado bioactividad (du Jardin, 2015). Es importante determinar el grado de bioactividad que tienen las SH con relación a su fuente de origen y el tipo de planta sobre las que se aplicará, para comprender sus efectos y de esta forma poder orientar el diseño de productos de utilidad agrícola como fitoestimulantes (Canellas et al., 2015). Sobre el mecanismo de acción, a nivel celular los $\mathrm{AH}$ activan la bomba $\mathrm{H}^{+}-\mathrm{ATPasa}$, incrementando el gradiente de hidrogeniones en la membrana celular, conduciendo al crecimiento ácido de la célula. El gradiente de hidrogeniones acidifica la pared celular, activando las enzimas que la ablandan, derivando en la expansión celular al limitarse la resistencia que la pared impone y la afluencia de agua al interior del citoplasma. De igual manera, se ha evidenciado que la efluencia de hidrogeniones al exterior de la membrana está acompañada por el influjo de iones calcio, lo que indica que se requiere la presencia de calcio en el medio para compensar la salida de iones hidrógeno, eventos que han sido relacionados con la elongación y diferenciación celular en la raíz derivada de la exposición a AH (Canellas et al., 2015). Por otra parte, Nardi et al. $(2009,2017)$ sugiere que las SH podrían inducir la producción de reguladores de crecimiento vegetal (RCVs) en la planta, lo que podría considerarse como evidencia del efecto fisiológico directo de estas sustancias sobre organismos vegetales.

Las SH pueden obtenerse de varias fuentes orgánicas, la más común son los carbones poco evolucionados, no comerciales debido a su bajo poder calorífico, denominados carbones de bajo rango (CBR), entre estos se encuentran la leonardita, la turba y el lignito, por su bajo grado de carbonificación estos carbones contienen un alto porcentaje de $\mathrm{MOH}$. En todos los casos es común la utilización de sustancias alcalinas para su extracción, no obstante, la $\mathrm{MOH}$ también puede obtenerse a partir de estos carbones mediante la utilización de microorganismos ligninolíticos, los cuales presentan la capacidad de biotransformar CBR y liberar las SH solubles presentes en la macroestructura (Valero et al., 2014).

Hay diferentes niveles de aproximación para determinar el efecto like-auxin de las SH (cuantificando las enzimas ATP-asas, su actividad o describiendo la expresión de sus genes, mediante metabolómica, analizando cambios metabólicos en la planta, describiendo cambios en la arquitectura de la raíz, mediante mediciones del crecimiento y proliferación de raíces y de la biomasa de la planta en general); así se ha descrito la bioactividad de una gran variedad de $\mathrm{AH}$ obtenidos de diferentes fuentes por el método convencional de extracción alcalina y se ha concluido que la bioactividad está relacionada con las características estructurales de las supramoléculas húmicas (Muscolo et al., 2013; Monda et al., 2017) . En trabajos previos se ha evaluado la obtención de SH a partir de CBR mediante la actividad de bacterias solubilizadoras de carbón (BSC) (Valero et al., 2011) y se ha caracterizado la estructura supramolecular de la fracción de $\mathrm{AH}$, concluyendo que presentan algunas diferencias en comparación con los $\mathrm{AH}$ obtenidos 
por el método clásico de extracción alcalina (Valero, 2013), pero aún no se ha determinado si este método de obtención cambia las propiedades bioactivas de los $\mathrm{AH}$, aun cuando preliminarmente se ha encontrado evidencia de bioactividad diferencial de estos $\mathrm{AH}$, mediante el desarrollo de experimentos de fitoestimulación en plantas de maíz (Pantoja et al., 2016).

El propósito de este trabajo fue probar una metodología rápida y sencilla que permitiera determinar el efecto like-auxin de $\mathrm{AH}$ obtenidos mediante la transformación microbiana de CBR, utilizando una cepa BSC, tomando como referencia la bioactividad de $\mathrm{AH}$ obtenidos mediante el método clásico de extracción alcalina y el efecto del AIA, lo anterior mediante la evaluación de parámetros de crecimiento celular aplicando la metodología del experimento clásico de elongación de coleóptilos en gramíneas (Yamada, 1954; Kefford, 1962; Rayle et al., 1970) y la producción y elongación de raíces; lo anterior con el propósito de contar con un test que pueda utilizarse como prueba de tamizaje para evaluar en poco tiempo y a bajo costo este parámetro de calidad de nuevos materiales húmicos utilizados cómo fitoestimulantes, lo cual puede contribuir a mejorar las normativas que evalúen y controlen su calidad en un posible mercado.

\section{MATERIALES Y MÉTODOS}

Para el logro de los objetivos planteados en el presente trabajo de investigación se establecieron una serie de experimentos dirigidos inicialmente a encontrar una concentración de auxina que sirviera como referencia para establecer el grado de actividad de las soluciones de $\mathrm{AH}$ a evaluar. Posteriormente se evaluó el efecto bioestimulador de $\mathrm{AH}$ obtenidos por extracción química y de $\mathrm{AH}$ obtenidos por solubilización utilizando Enterobacter aerogenes, para finalmente comparar los resultados obtenidos en cada caso. Los métodos utilizados se describen a continuación:

\section{Determinación de la concentración de AIA de referencia}

Se estableció un experimento dirigido a determinar la concentración de AIA (ácido indolacético) con el mayor efecto sobre el alargamiento de coleóptilos a partir de semillas germinadas de Triticum aestivum L., para lo cual se sometieron semillas recién germinadas a diferentes concentraciones de dicho regulador de crecimiento vegetal (RCV) $(0,0 ; 1,0 ; 2,0 ; 5,0$ y 10 ppm). Todas las soluciones de AIA fueron diluidas en una solución de $\mathrm{CaCl}_{2} 2,0 \mathrm{mM}$ y el tratamiento control (0,0 ppm de AIA) consistió de únicamente la solución de $\mathrm{CaCl}_{2}$. En todos los casos el pH fue ajustado a 6,5. Se estableció al AIA como control positivo al ser este regulador representativo del grupo de las auxinas y tener abundante soporte bibliográfico sobre sus efectos en procesos que afectan la formación y elongación de tallos y raíces en múltiples especies, entre éstas $T$. aestivum L. (Rekoslavskaya et al., 1999; Akbari et al., 2007). Las semillas de trigo desinfectadas fueron llevadas a germinación en condiciones de esterilidad y oscuridad en cámara húmeda durante 48 horas a una temperatura de $28^{\circ} \mathrm{C}$, una vez fue evidente la germinación, se seleccionaron 8 semillas que tuvieran ruptura de la testa y exposición de la radícula visible, sobre estas semillas se aplicaron los tratamientos descritos previamente y se llevaron a oscuridad por 72 horas, finalmente se registró la longitud alcanzada por los coleóptilos, adicionalmente, como variables confirmatorias del efecto like auxin, se registró el número y longitud promedio de las raíces desarrolladas.

\section{Evaluación de la actividad bioestimuladora de AH en T. aestivum L.}

Para determinar el efecto like-auxin de $\mathrm{AH}$ obtenidos de CBR se utilizaron extractos producidos mediante dos métodos de extracción: Extracción Química con $\mathrm{NaOH}(\mathrm{AH}-\mathrm{Q})$ a partir de un CBR tipo lignito, teniendo en cuenta la metodología clásica sugerida por la "International Humic Substance Society" (IHSS, 2007) y Than (2010), descrita por Valero et al. (2014) y Extracción Biológica con una cepa de Enterobacter aerogenes (AH-B), la cual fue seleccionada en una investigación previa por presentar alta actividad transformadora de CBR con producción de SH (Valero et al., 2014), esta cepa hace parte de la colección de BSC mantenida en el Laboratorio de Microbiología Agrícola y Ambiental de la Universidad Popular del Cesar, esta cepa estaba conservada en medio de cultivo Agar Carbón (Valero et al., 2012) con el fin de que no pierda la capacidad solubilizadora de CBR; la extracción de AH-B se realizó siguiendo el protocolo descrito por Valero et al. (2014). Para estos experimentos se incluyó como un tratamiento de referencia, la concentración de AIA que presentó el mayor efecto estimulador en el experimento anterior.

\section{Determinación de la bioactividad de AH-Q}

Con el fin de establecer la concentración de $\mathrm{AH}-\mathrm{Q}$ con el mayor efecto biostimulador, se germinaron semillas de $T$. aestivum L. bajo condiciones de oscuridad y asepsia en cámara húmeda durante 48 horas, a una temperatura de $28^{\circ} \mathrm{C}$. Posteriormente se seleccionaron 35 semillas que tuvieran la radícula visible, se distribuyeron independientemente en tratamientos consistentes de cinco concentraciones de $A H-Q$ (2,0; 20; 40; 80 y 150 mg C* $\left.\mathrm{L}^{-1}\right)$, se utilizó una solución de AIA (2,0 ppm, determinada en el primer experimento) como referencia y un tratamiento control sin sustancias estimuladoras del crecimiento $\left(\mathrm{CaCl}_{2} 2 \mathrm{H}_{2} \mathrm{O} 2,0 \mathrm{mM}\right)$. 
Tanto los AH como el AIA fueron disueltos en una solución de $\mathrm{CaCl}_{2} 2 \mathrm{H}_{2} \mathrm{O} 2,0 \mathrm{mM}$ y el pH se ajustó a 6,5 con $\mathrm{NaOH}$ y HCl $(0,5 \mathrm{~N})$ de acuerdo con lo expuesto por Canellas et al. (2011) y Barros et al. (2010). Las semillas tratadas se llevaron a oscuridad por 72 horas y se registró el valor final de las variables (longitud del coleóptilo, número y longitud promedio de raíces).

\section{Efecto fitoestimulador ocasionado por AH-B vs AH-Q y AIA en semillas de T. aestivum L.}

El ensayo se desarrolló bajo las mismas condiciones de los experimentos anteriores; en este ensayo se utilizaron como referencias las concentraciones de AIA y AH-Q que tuvieron mayor efecto fitoestimulador (según los resultados de los dos ensayos anteriores) y se compararon con los efectos ocasionados por el tratamiento con soluciones de AH-B de 20, 40, 80 y 150 ppm, con el propósito de relacionar la bioactividad de los AH con el tipo de extracción. La aplicación de AIA se utilizó como un control positivo en el experimento, debido a que en este tratamiento se evidencian los efectos hormonales típicos de las auxinas.

\section{Análisis estadístico}

Todos los experimentos fueron ajustados a un diseño completamente aleatorizado. Los datos fueron graficados, analizados mediante ANOVA y las medias de cada tratamiento fueron separadas mediante el test de comparaciones múltiples de Tukey utilizando el programa de análisis estadístico SigmaPlot v. 11.

\section{RESULTADOS Y DISCUSIÓN}

Se estableció que la concentración de AIA que mayor efecto tiene sobre el alargamiento celular en los coleóptilos de semillas de trigo recién germinadas es de 2,0 $\mathrm{mgL}^{-1}$, este efecto se corroboró observando a la vez el mayor incremento en el número y longitud de raíces desarrolladas (Figura 1). La estimulación de la formación de raíces mediante la aplicación exógena de auxinas se conoce desde la década de 1930, cuando se comprobó que varias especies vegetales desarrollaban raíces laterales en presencia de AIA; entre éstas están cereales pertenecientes a los géneros Avena, Zea y Triticum (Torrey, 1950).
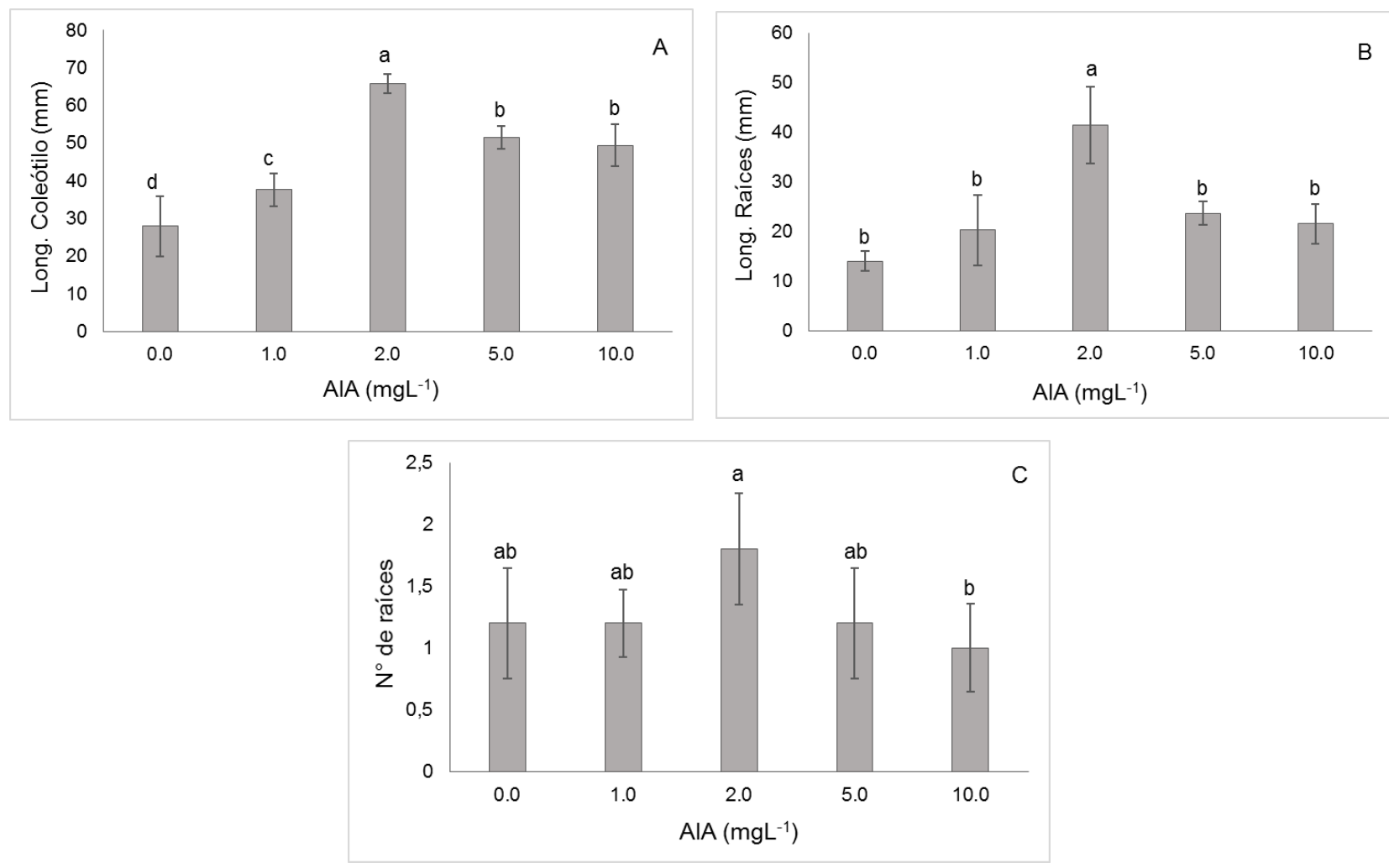

Fig.1: Efecto del AIA sobre los parámetros de crecimiento de plántulas de trigo, A. Long. Coloéptilos, B. Long. Raíces, $\mathrm{C}$. Número de raíces. Cada barra corresponde a la media de un tratamiento \pm la desviación estándar. Barras con letras diferentes indican diferencias estadísticamente significativas $(\alpha=0,05)$.

Como ha sido descrito, el efecto like-auxin de las SH se debe a la estimulación de una respuesta de alargamiento en las células vegetales similar al provocado por las auxinas, lo que se conoce como crecimiento ácido, el cual es promovido por la acumulación de hidrogeniones en el apoplasto como 
consecuencia de la actividad $\mathrm{H}^{+}-$ATPasa (Canellas y Olivares, 2014). Con base a lo anterior, al evaluar el efecto de los AH-Q se evidenció que la concentración de $40 \mathrm{mg} \mathrm{C.L^{-1 }}$ fue la que indujo un mayor alargamiento del coleóptilo y raíces (Figura 2). Dichos resultados indican una mayor actividad de los AH-Q a dicha concentración, en comparación con la solución de AIA que desencadenó el mayor efecto $\left(2,0 \mathrm{mgL}^{-1}\right)$, evidenciándose diferencias estadísticamente significativas en la respuesta de las plántulas a dichos tratamientos $(P \leq 0,001)$. De igual manera, alrededor de dicha concentración, el efecto de AH-Q fue menos marcado, mostrando una distribución típica donde la respuesta a una determinada sustancia estimuladora va incrementado conforme al incremento de la concentración de la misma, hasta un punto máximo, después del cual la concentración se vuelve inhibitoria. El efecto de las auxinas en la promoción del crecimiento vegetal, al igual que otros RCVs, ha sido descrito por una curva, donde se alcanza un máximo efecto en una concentración intermedia, se tienen varios ejemplos en Poaceae (Mahmood et al., 2012). Akhtar et al. (2015) encontraron que la aplicación de $\mathrm{AH}$ en plantas de trigo cultivadas en campo, en un rango entre 1,0 y $2,5 \mathrm{Kg} \mathrm{ha}^{-1}$, no tuvo efecto sobre la emergencia de las semillas, más sí hubo estimulación del crecimiento, evidenciado como incremento en la longitud de las plantas.
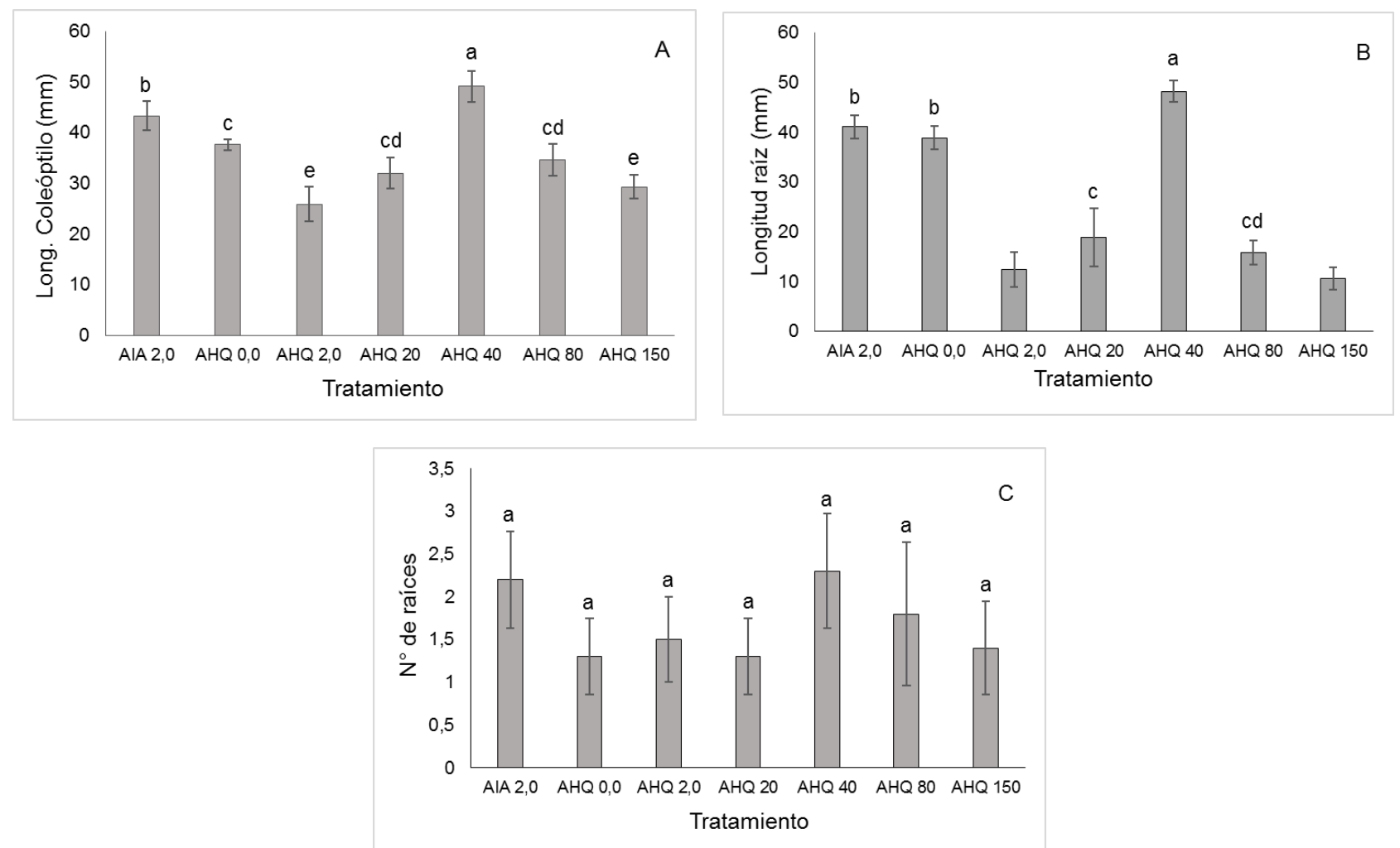

Fig. 2: Bioactividad de ácidos húmicos extraídos por método químico sobre los parámetros de crecimiento de plántulas de trigo. A: Long. del coleóptilo, B: Long. raíces, C: Número de raíces. Unidades: AIA (mg.L' 1), AH-Q $\left(m g C . L^{-1}\right)$. Cada barra corresponde a la media de un tratamiento \pm la desviación estándar. Barras con letras diferentes indican diferencias estadísticamente significativas $(\alpha=0,05)$.

Suárez et al. (2009) evaluaron el efecto de diferentes concentraciones de ácido naftalén-acético (ANA) sobre el enraizamiento de tallos micropropagados de caña flecha (Gynerium sagittatum Aubl.), estableciendo que desde 0,5 hasta $7,0 \mathrm{mgL}^{-1}$ dicho regulador de crecimiento induce la formación de raíces y que este efecto es directamente proporcional a la concentración de ANA en el medio de cultivo, resultados muy superiores a los registrados cuando el medio de cultivo no se suplementó con la auxina o con carbón activado $\left(100 \mathrm{mgL}^{-1}\right)$.

En el presente trabajo de investigación no se evidenciaron diferencias estadísticamente significativas en el número promedio de raíces obtenidas por tratamiento $(P=0,071)$, no obstante, el comportamiento de la variable en cada uno de los tratamientos fue similar al de las otras variables evaluadas, evidenciándose un mayor número de raíces en el tratamiento con $40 \mathrm{mg} \mathrm{C}^{-\mathrm{L}^{-1}}$ de $\mathrm{AH}-\mathrm{Q}$, bajo el cual se obtuvo un promedio muy cercano al registrado en el control positivo (AlA 2,0 $\mathrm{mgL}^{-1}$ ) (Figura 2C). Pastrana y Suárez (2009) encontraron que la formación de raíces en caña flecha no está influenciada por el suministro exógeno de ANA, pero que el mismo incrementa el número de raíces que pueden formarse de novo, sin ningún efecto sobre la longitud de las mismas. De manera similar, Akbari et al. (2007) encontraron que el AIA no afecta la longitud de la radícula en plántulas de trigo recién germinadas, mas sí promovía la elongación del hipocotilo. 
El resultado del ensayo dirigido a comparar el grado de bioactividad de los $\mathrm{AH}-\mathrm{B}$ frente al de los $\mathrm{AH}-\mathrm{Q}$ en la concentración que generó la mejor respuesta, indica que los AH-B presentan mayor actividad a una

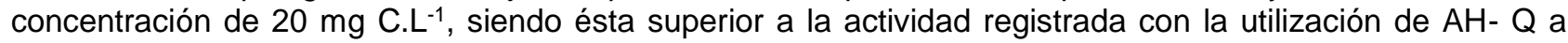
una concentración de $40 \mathrm{mgC}^{-\mathrm{L}^{-1}}$, en todos los parámetros de crecimiento evaluados (Figura 3). Sobre este aspecto, Canellas y Olivares (2014) comprobaron que la fuente de los AH incide sobre el efecto de los mismos sobre el crecimiento vegetal, mostrando una mayor capacidad estimuladora del crecimiento por parte de sustancias extraídas a partir de sustratos compostados (turba, vermicompost), donde necesariamente han intervenido microorganismos. Adicional a esto, Scaglia et al. (2016) resaltan el efecto de "actividad hormonal inducida" por AH obtenidos a partir de vermicompost, sosteniendo que el mismo es una buena fuente de sustancias estimuladoras del crecimiento vegetal, las cuales derivan, por un lado, de las transformaciones mecánicas que realizan las lombrices sobre su alimento y por otro lado, de las modificaciones químicas que hacen los microorganismos asociados al tubo digestivo de ésta sobre la materia orgánica que está siendo digerida. No obstante, Trevisán et al. (2010) plantean que además de la fuente, deben considerarse otros factores, tales como la concentración de $\mathrm{SH}$, la especie vegetal utilizada, la edad de la misma y las condiciones de cultivo.
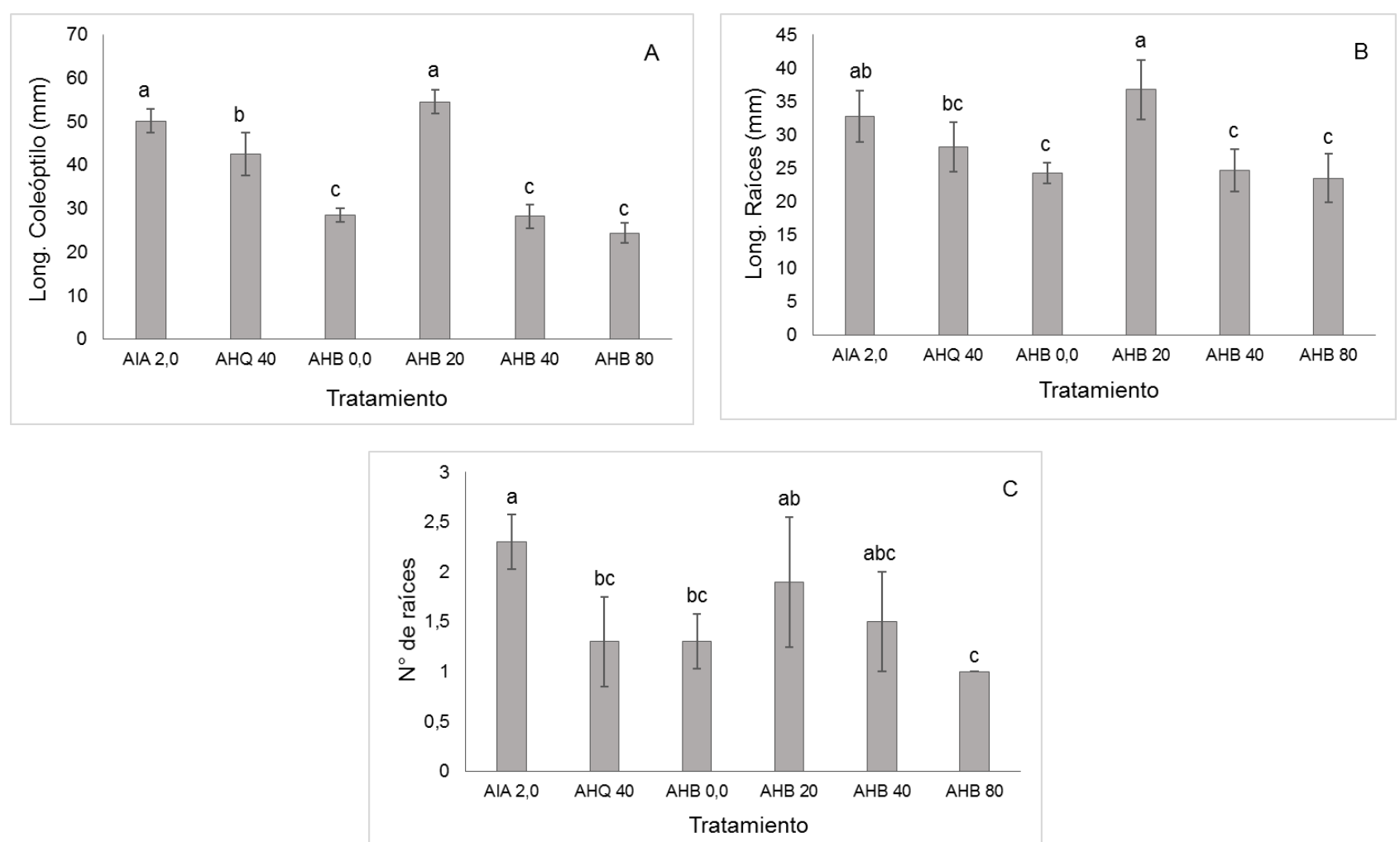

Fig. 3: Comparación entre el efecto de los ácidos húmicos extraídos biológicamente vs el efecto de los ácidos húmicos extraídos químicamente, sobre los parámetros de crecimiento de plántulas de trigo. A: Long. del coleóptilo, B: Long. raíces, C: Número de raíces. Unidades: AIA (mg. $\left.\mathrm{L}^{-1}\right), A H$ $\left(\mathrm{mgC} \mathrm{L}^{-1}\right)$. Cada barra corresponde a la media de un tratamiento \pm la desviación estándar. Barras con letras diferentes indican diferencias estadísticamente significativas $(\alpha=0,05)$.

Valero et al. (2014) obtuvieron BSC que liberan SH a partir de CBR y se comparó a nivel supramolecular la fracción de $\mathrm{AH}$ producidos por estas bacterias frente a $\mathrm{AH}$ extraídos químicamente, se encontró que los $\mathrm{AH}$ presentes en el CBR son transformados estructuralmente por las BSC, generando supramoléculas que conservan el grado de humificación, pero presentan mayor polidispersidad y peso molecular, disminución en el contenido de $\mathrm{O}_{2}$, están enriquecidas en nitrógeno, exhiben menor grado de condensación aromática y presentan predominio de moléculas alifáticas polares que incluyen derivados de ácidos grasos que solamente pueden ser sintetizados por actividad microbiana. Debido a estas características diferenciales los $\mathrm{AH}-\mathrm{B}$ podrían determinar un tipo y nivel de bioactividad diferente al de $\mathrm{AH}$ - $\mathrm{Q}$.

Es posible que los microorganismos propios de la rizósfera incidan sobre las $\mathrm{SH}$ conllevando a que interactúen mejor con las células vegetales, o que estas $\mathrm{SH}$ tengan sitios en su estructura que permitan una captura más eficiente de los RCVs presentes en la rizósfera, producto de un proceso de coevolución. De acuerdo con Canellas y Olivares (2014), la supraestructura y la actividad de las SH están muy relacionadas con las uniones hidrofóbicas e hidrofílicas (puentes de hidrógeno) propias de estos compuestos. Canellas et al. (2011) realizaron experimentos donde se aislaron SH de extractos complejos, comprobando que la actividad de esas sustancias se relacionaba íntimamente con las moléculas débilmente unidas y de 
naturaleza hidrofóbica, las cuales son producidas por microorganismos. Canellas y Olivares (2014) sugieren que las SH pueden inducir la producción de fitohormonas, lo cual puede ser probable en los experimentos realizados en este trabajo. Aparte, las moléculas de las SH son muy diversas y evidentemente el método de extracción química generará siempre extractos de constitución diferente con relación a las moléculas presentes o a su concentración, no obstante, este mismo principio no podría generalizarse para el uso de las BSC, ya que su metabolismo puede disponer de vías que generen determinado tipo de moléculas.

Con relación al efecto sobre la producción de raíces, claramente se nota el efecto like-auxin de los $\mathrm{AH}$ - B, pudiendo probablemente relacionar la actividad $\mathrm{H}^{+}$-ATPasa con el número de raíces producidas en presencia de los AH. Canellas y Olivares (2014) y Ramos et al. (2015) reconocen esto como bioestimulación y explican que la producción de raíces se debe al influjo de $\mathrm{Ca}^{2+}$ al interior de la célula como consecuencia del eflujo de $\mathrm{H}^{+}$, lo que a su vez implica un mayor crecimiento en otros órganos de la planta como consecuencia de una mejor toma de nutrientes desde la solución nutritiva.

Finalmente, se puede considerar que los resultados apoyan el diseño una metodología sencilla y relativamente rápida para la evaluación de los efectos bioactivos de productos fitoestimulantes a base de $\mathrm{MOH}$; esto resulta conveniente teniendo en cuenta que las técnicas de caracterización aplicadas en investigación, tales como la resonancia magnética nuclear, la espectroscopía infrarroja, termoquemólisis, metabolómica, expresión de enzimas ATP-asas, y expresión de genes, pueden resultar costosas y pocos laboratorios pueden estar en capacidad de llevarlas a cabo como análisis de rutina de calidad.

\section{CONCLUSIONES}

A manera de conclusión, la evidencia encontrada en el presente trabajo indica que los $\mathrm{AH}-\mathrm{Q}$ a una concentración de $40 \mathrm{mgC}^{-1}$ ocasiona en las semillas de trigo recién germinadas la típica respuesta auxínica del crecimiento celular responsable del alargamiento del coleóptilo, acompañada de la tendencia a la proliferación de raíces y el alargamiento de las mismas; estas respuestas resultan comparables en magnitud al efecto ocasionado por una concentración de 2,0 $\mathrm{mgL}^{-1}$ de AIA; igualmente se confirmó que los AH-B también desencadenan el efecto like auxin, pero se consigue la mayor estimulación del crecimiento celular a una concentración menor $\left(20 \mathrm{mgC}^{-1}\right)$ en comparación con los AH-Q, e igualmente comparable en magnitud al efecto ocasionado por el AIA a 2,0 $\mathrm{mgL}^{-1}$.

Los resultados obtenidos también indican que el ensayo típico de alargamiento de coleóptilos de gramíneas (en este caso Trigo) es pertinente para evaluar la bioactividad de materiales húmicos, con estudios adicionales para una mejor estandarización, podría generarse un test sencillo para la evaluación rápida y económica tanto para trabajos académicos como para la evaluación de calidad de productos fitoestimulantes a base de $\mathrm{MOH}$.

\section{REFERENCIAS}

Akbari, G., S. Modaress y S. Yousefzadeh, Effect of auxin and salt stress (NaCl) on seed germination of wheat cultivars (Triticum aestivum L.), Pakistan Journal of Biological Sciences, 10(15), 2557-2561 (2007)

Akhtar, K., A. Khan, M. Tariq Jan, M. Zahir Afridi, S. Ali y S. Zaheer, Effect of humic acid and crop residue application on emergence and wheat phenology, Pure Applied Biology, 4(1), 97-103 (2015)

Barros, L., L. Canellas, F. Lopes, N. Oliveira, E. La' Zaro y A. Piccolo, Bioactivity of chemically transformed humic matter from vermicompost on plant root growth, Journal Agric. Food Chem., 58, 3681-3688 (2010)

Canellas, L., D. Dantas y otros ocho autores, Probing thehormonal activity of fractionated molecular humic components in tomatoauxin mutants, Annals of Applied Biology, 159(2), 202-211 (2011)

Canellas, L. y F. Olivares, Physiological responses to humic substances as plant growth promoter, Chemical and Biological Technologies in Agriculture, 1,3 (2014)

Canellas, L., F. Olivares y otros cinco autores, Humic and fulvic acids as biostimulants in horticulture, Scientia Horticulturae, 196, 15-27 (2015)

Delatorre, P., J. Silva y otros ocho autores, Interactions between indole-3-acetic acid (IAA) with a lectin from Canavalia maritima seeds reveal a new function for lectins in plant physiology, Biochimie, 95(9), 1697-1703 (2013)

du Jardin, P., Plant biostimulants: Definition, concept, main categories and regulation, Scientia Horticulturae, 196, 3-14 (2015)

Gallavotti, A., The role of auxin in shaping shoot architecture, Journal of Experimental Botany, 64(9), 2593-2608 (2013)

International Humic Substances Society (IHSS), Isolation of IHSS Soil Fulvic and Humic Acids, IHSS (2007)

Kefford, N., Auxin-gibberellin interaction in rice coleoptile elongation, Plant Physiology, 37, 380-386 (1962)

Mahmood, I., A. Razzaq, Z. Khan, I. Hafiz y S. Kaleem, Evaluation of tissue culture responses of promising wheat (Triticum aestivum L.) cultivars and development of efficient regeneration system, Pakistan Journal of Botany, 44, 277284 (2012) 
Monda, H., H. Cozzolino, G. Vinci, R. Spaccini y A. Piccolo, Molecular characteristics of water-extractable organic matter from different composted biomasses and their effects on seed germination and early growth of maize, Science of the Total Environment, 590-591, 40-49 (2017)

Muscolo, A., F. Bovalo, F. Gionfriddo y S. Nardi, Earthworm humic matter produces auxin-like effects onDaucus carota cell growth and nitrate metabolism, Soil Biology and Biochemistry, 31(9), 1303-1311 (1999)

Muscolo, A., M. Sidari y S. Nardi, Humic substance: Relationship between structure and activity. Deeper information suggests univocal findings, Journal of Geochemical Exploration, 129, 57-63 (2013)

Nardi, S., D. Pizzeghello, A. Muscolo y A. Vianello, Physiological effects of humic substances on higher plants, Soil Biology \& Biochemistry, 34, 1527-1536 (2002)

Nardi, S., P. Carletti, D. Pizzeghello y A. Muscolo, Biological activities of humic substances, en Biophysico-Chemical Processes Involving Natural Non Living Organic Matter in Environmental Systems. Vol 2, part 1: fundamentals and impact of mineral-organic biota interactions on the formation, transformation. Turnover and storage of natural nonliving organic matter (NOM) por Senesi, N., Xing, B. y Huang, P. (Eds.), pp. 305-340 Wiley, New Jersey, USA (2009)

Nardi, S., D. Pizzeghello y A. Ertani, Hormone-like activity of the soil organic matter, Applied Soil Ecology, DOI: http://dx.doi.org/10.1016/j.apsoil.2017.04.020, Applied Soil Ecology, en prensa, mayo (2017)

Pantoja, M., Y. Almanza y N. Valero, Evaluación del efecto Auxin- Like de ácidos húmicos en maíz mediante análisis digital de imágenes, Revista UDCA, Actualidad y Divulgación Científica, 19(1), 361- 369 (2016)

Pastrana, I. e I. Suárez, Producción de plantas de caña flecha (Gynerium sagitatum Aubl.) "Criolla" a través de micropropagación, Revista Temas Agrarios, 14(2), 2-18 (2009)

Piccolo, A., The supramolecular structure of humic substances: $A$ novel understanding of humus chemistry and implications in soil science, Advances in Agronomy, 75, 57-134 (2002)

Piccolo, A., The nature of sol organic matter and innovative soil managementto fight global changes and maintain agricultural productivity, en Carbon Sequestration in Agricultural Soils: a Multidisciplinary Approachto Innovative Methods por Piccolo, A. (Ed.)., pp 1-20 Springer, Heidelberg, Alemania (2012)

Ramos, A., L. Dobbss, L. Santos, M. Fernandes, F. Olivares, N. Aguiar y L. Canellas, Humic matter elicits proton and calcium fluxes and signaling dependent on $\mathrm{Ca}^{2+}$-dependent protein kinase (CDPK) at early stages of lateral plant root development, Chemical and Biological Technologies in Agriculture, 2:3 (2015)

Rayle, D., M. Evans y R. Hertelt, Action of Auxin on Cell Elongation. Proceedings of the National Academy of Sciecnce, 65(1), 184-191 (1970)

Rekoslavskaya, N., O. Yurjeva, R. Salyaev, S. Mapelli y T. Kopytina, D-Tryptophan as IAA source during wheat germination, Bulgarian Journal of Plant Physiology, 25(1-2), 39-49 (1999)

Scaglia, B., R. Nunes, M. Olveira, F. Tambone y F. Adani, Investigating organic molecules responsible of auxin-like activity of humic acid fraction extracted from vermicompost, Science of the Total Environment, 562, 289-295 (2016)

Suárez, I., H. Aramendiz e I. Pastrana, Micropropagación de caña flecha (Gynerium sagitatum Aubl.), Revista Facultad Nacional de Agronomía - Medellín, 62(2), 5135-5143 (2009)

Tan, K.H., Principles of soil chemistry, CRC press, Boca Raton, USA (2010)

Torrey, J., The Induction of Lateral Roots by Indoleacetic Acid and Root Decapitation, American Journal of Botany, 37(4), 257-264 (1950)

Trevisán, S., O. Francioso, S. Quaggiotti y S. Nardi, Humic substances biological activity at the plant-soil interface from environmental aspects to molecular factors, Plant Signaling \& Behavior, 5(6), 635-643 (2010)

Valero, N., J. Beleño y S. Mancilla, Biotransformación de carbón de bajo rango por bacterias aisladas de microhábitats influenciados por residuos de carbón, Revista Colombiana de Biotecnología, 13(1), 58-65 (2011)

Valero, N., L. Rodríguez, S. Mancilla y L. Contreras, Obtención de bacterias biotransformadoras de carbón de bajo rango a partir de microhábitats con presencia de residuos carbonosos, Acta biológica Colombiana, 17(2), 335-348 (2012)

Valero, N., Transformación microbiana de carbón de bajo rango para inducir cambios en las propiedades del suelo, Tesis de Doctorado, Facultad de Ciencias Agropecuarias, Universidad Nacional de Colombia, Bogotá D.C., Colombia (2013)

Valero, N., L. Gómez, M. Pantoja y R. Ramírez, Production of humic substances through coal-solubilizing bacteria, Brazilian Journal of Microbiology, 45(3), 911-918 (2014)

Yamada, N., Auxin relationships of the rice coleoptile, Plant Physiology, 29, 92-96 (1954) 